International Journal of Biology, Pharmacy and Allied Sciences (IJBPAS) 'A Bridge Betusen Caboratory and QRader'

WwW.ibpas.com

\title{
RECONSTRUCTING THE VERTICAL DIMENSION: A CASE REPORT
}

\section{SHAH $\mathbf{1}^{1^{*}}$ AND NALLASWAMY $\mathbf{D}^{2}$}

1: Post-graduate student, Department of Prosthodontics and Implant Dentistry, Saveetha Dental College, Saveetha Institute of Medical and Technical Sciences, Chennai, India 2: Director of Academics, Saveetha Dental College, Saveetha Institute of Medical and Technical Sciences Chennai, India

*Corresponding Author: Dr. Simone Shah: E Mail: simoneshah2293@gmail.com; Ph.

$$
\text { No. : }+91 \text { - } 8879272111
$$

Received $2^{\text {nd }}$ April 2020; Revised $21^{\text {st }}$ April 2020; Accepted $14^{\text {th }}$ July 2020; Available online $1^{\text {st }}$ Jan. 2021 https://doi.org/10.31032/IJBPAS/2021/10.1.5328

\section{ABSTRACT}

Full mouth rehabilitation of a patient is challenging. It does not only rehabilitate the teeth, it also maintains a healthy stomatognathic system. To define the goals of treatment the various biological, functional and structural factors must be considered. A fully functional and biologically stable state between the teeth, the periodontal structures, the muscles of mastication as well as the temporomandibular joint is obtained. All these mechanisms function together in synchronous harmony. Thus, a thorough approach is necessary to achieve the ideal outcome. Tooth wear can be physiological as well as a pathological change in the tooth shape and form due to trauma, grinding, excessive clenching or developmental changes. The vertical dimension of occlusion is generally maintained by the tooth eruption and the alveolar bone growth. As the teeth wear the alveolar bone adapts and compensates for the loss of tooth structure to maintain the vertical dimension of occlusion. Patients with generalized attrition most often complain of generalized sensitivity, pain in the muscles of mastication on chewing, clenching and grinding of teeth etc. In such cases there is excessive loss in vertical dimension.

Thus, a full mouth rehabilitation is suggested as a definitive treatment plan for the patient. This case report details the full mouth rehabilitation of a patient with severely worn teeth.

Keywords: full mouth rehabilitation, Bruxism, metal ceramic crowns, vertical dimension 


\section{INTRODUCTION}

Rehabilitation of the full mouth is a long process with multiple steps involved. This rehabilitation improves the health of the whole masticatory system [1]. The teeth, periodontal structures, the masticatory muscles and temporomandibular joints function together in harmony [2]. The change in vertical dimension of occlusion is caused due to chronic tooth wear leading to muscle strain and hypertrophy [3]. This phenomena is commonly seen in patients with bruxism [4]. Chronic prolonged bruxism leads to generalized attrition and wear of the teeth. It is a pathologic activity of the stomatognathic system involving grinding of the tooth during parafunctional movements [5]. The clinical signs of bruxism are mostly related to dental wear and muscular and joint discomforts, but a large number of etiological factors can be listed, as local, systemic, psychological and hereditary factors [6]. The etiology of bruxism is quite uncertain and could have multiple causes like genetic factors, positional and structural abnormalities, psychosocial factors, anxiety, insomnia, depression, smoking, alcohol consumption, macrotrauma, systemic diseases, gastroesophageal reflux and certain medications [7]. With advancing age, people suffer from multiple craniofacial changes and the bony support drops,corners of the mouth are dropped down, nasal tip drops, upper lip lengthens and development of jowls occurs [8]. This leads to multiple challenges in treating this patient and an appropriate treatment plan is essential for the success of the treatment for this patient.

This case report details the full mouth rehabilitation of a patient with severely worn and multiple missing teeth.

\section{PRESENTATION OF THE CASE:}

An 80 year old male patient reported to the Department of Prosthodontics Saveetha Dental College with the chief complaint of difficulty in chewing and replacement of multiple missing teeth. The medical history of the patient was- he was a diabetic since the last 10 years and was under medication and had a history of hypertension since the last 10 years as well. The Patient had a positive history of night grinding and pain in the muscles of mastication after waking up.

\section{CLINICAL DIAGNOSIS:}

The patient has a straight frontal profile with drooping corners of the mouth. There were multiple wrinkle lines around the mouth and the face. The vertical dimension of the patient was completely collapsed when seen from the profile view (Figure 1). 


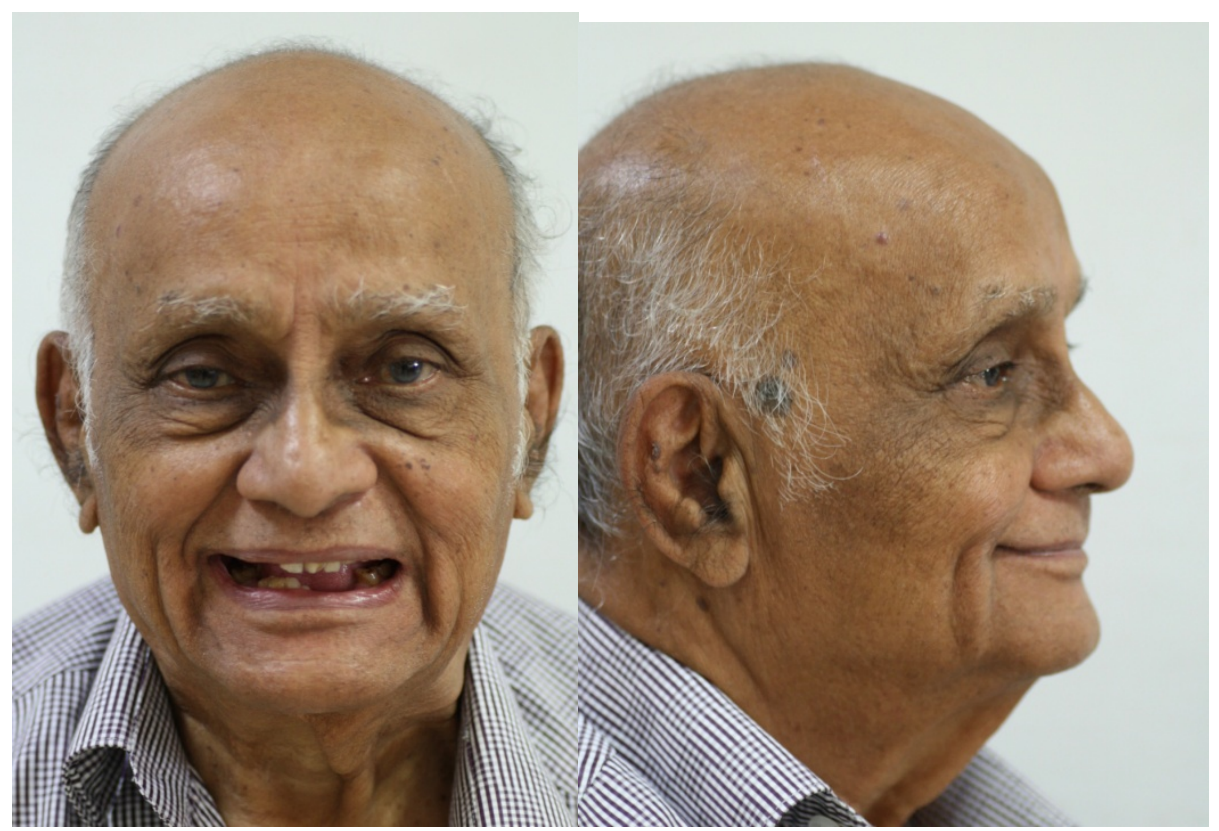

Figure 1: Pre operative Extraoral frontal and profile - Smile

On examination, the patient experienced pain in the muscles of mastication Masseter and Temporalis.

To determine if the Vertical dimension was altered the following criteria were evaluated:

1. History of Wear: Patients had a habit of nocturnal bruxism and pain in the muscles of mastication.

2. Phonetic Evaluation: Excessive loss of vertical dimension leads to altered $\mathrm{s}$ and $\mathrm{f}$ sounds.

3. Interocclusal Space: The interocclusal space - Vertical Dimension at rest as well as occlusion-difference in the space was $8 \mathrm{~mm}$. A freeway space of 2 $\mathrm{mm}$ is required for normal phonetics. Thus there was a loss of $6 \mathrm{~mm}$ in the vertical dimension.

4. Facial appearance: Drooping commissures around the mouth were observed (Figure 2).

\section{INTRAORAL EXAMINATION:}

On Intraoral examination; the patient had generalized attrition and wear facets which were present on all the teeth. Anterior deep bite, buttressing of the bone in the mandibular anterior was seen due to occlusal trauma. A class 3 maxillomandibular relationship with and edge to edge anterior bite. There was a discrepancy of around 2-3 $\mathrm{mm}$ between the centric relation and maximum intercuspation. Missing teeth wrt 12, 25, 35, 36, 41, 42, 43, 44 (Figure 3, 4, 5). 


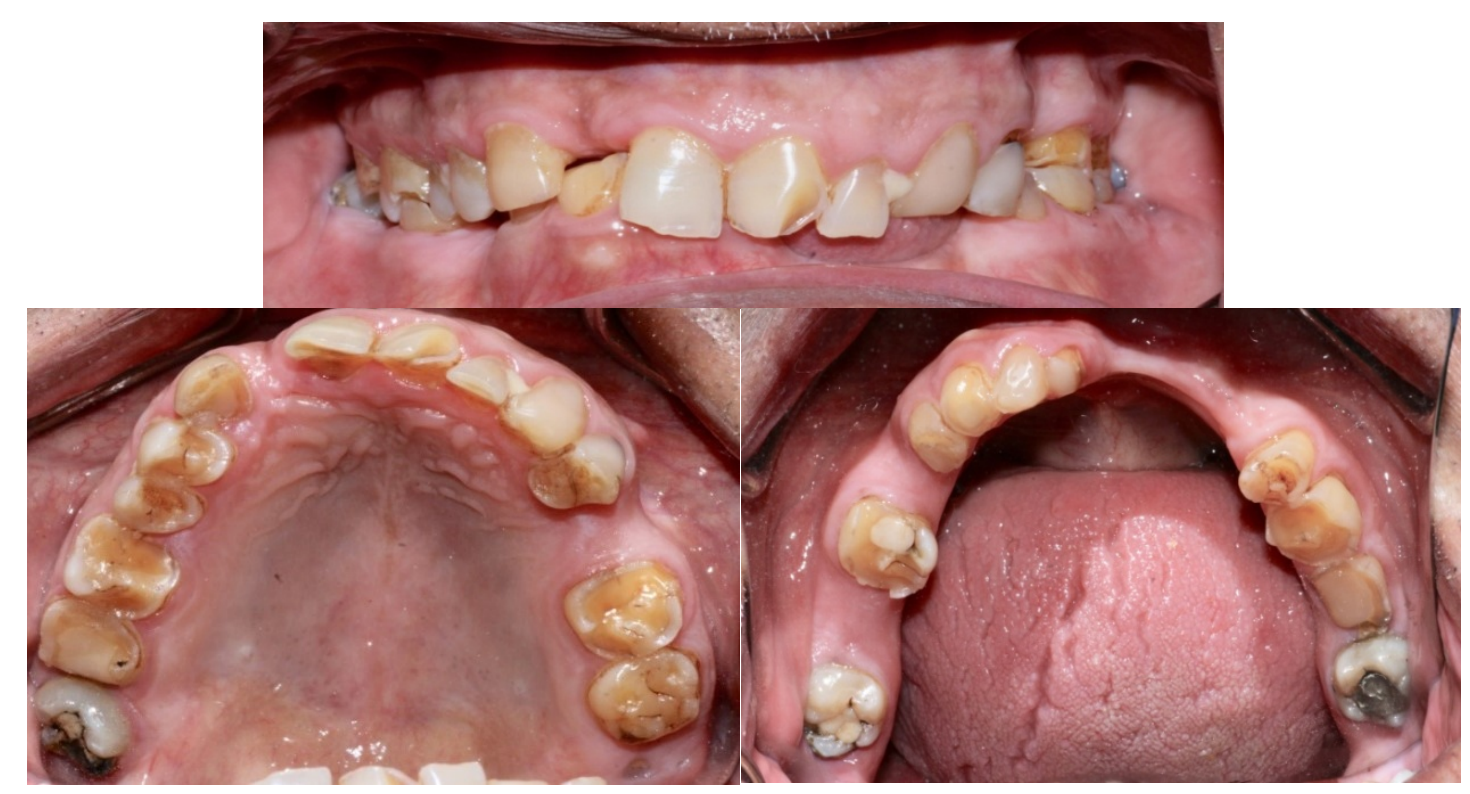

Figure 2: Pre-operative Intraoral frontal in centric, pre-operative Maxillary occlusal, pre-operative mandibular

MANAGEMENT:

On the first appointment, Diagnostic casts were obtained. Following this the facebow transfer was completed. The vertical dimension was increased by $6 \mathrm{~mm}$. The centric relation position was recorded at the increased vertical dimension using CADbite (IvoclarVivadent *Schaan) bite registration material and the casts were mounted on a semi adjustable articulator. Diagnostic wax up was made on the semiadjustable articulator at the increased vertical dimension (Figure 3).

Following this, $2 \mathrm{~mm}$ Laser Crown lengthening was done in relation to the mandibular anterior teeth.

Tooth preparations were done in the maxillary and mandibular teeth

Double cord packing was done with 000 and 00 cords.Master Impressions were made using the two step putty wash technique with Putty Elite HD Normal set
(Zermac;Italy) and Light body normal set Elite HD (Zermac; Italy) (Figure 4). The jaw relation was recorded with maxillary and mandibular occlusal rims at an increased vertical dimension of $6 \mathrm{~mm}$.

Facebow record was taken using the UTS 3D (IvoclarVivadent) .The die sectioned casts were mounted using the jaw relation record using the facebow on the Stratos 300 semi-adjustable articulator.

Cobalt Chromium framework trial of the maxillary and mandibular teeth were done following this (Figure 5).

The Ceramic framework trial was done with an established Class 1 mutually protected occlusion. Once the ceramic trial was satisfactory the crowns were glazed and cemented with Glass ionomer cement (GC Gold Label, Japan) (Figure 6, 7). A soft splint (night guard) was given to the patient to use every night. The patient was recalled every 3 months for check up. 


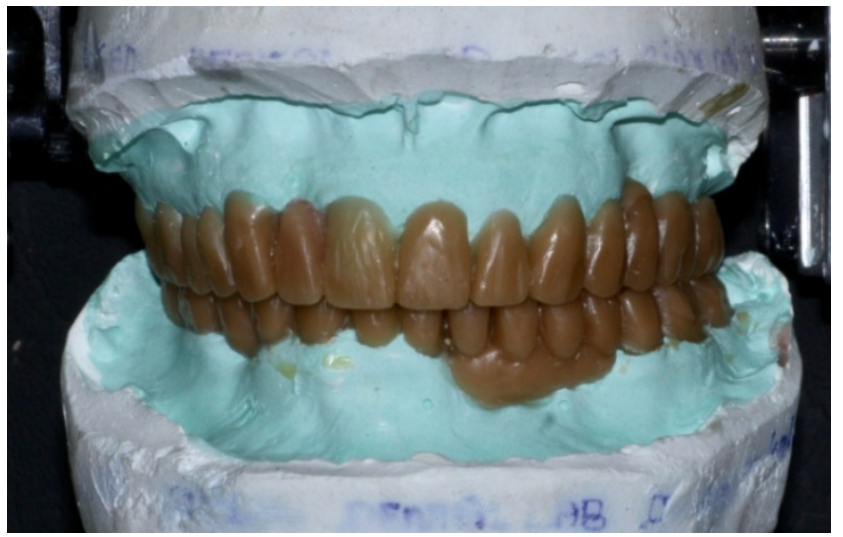

Figure 3: Full mouth Wax up on Stratos 300 Articulator

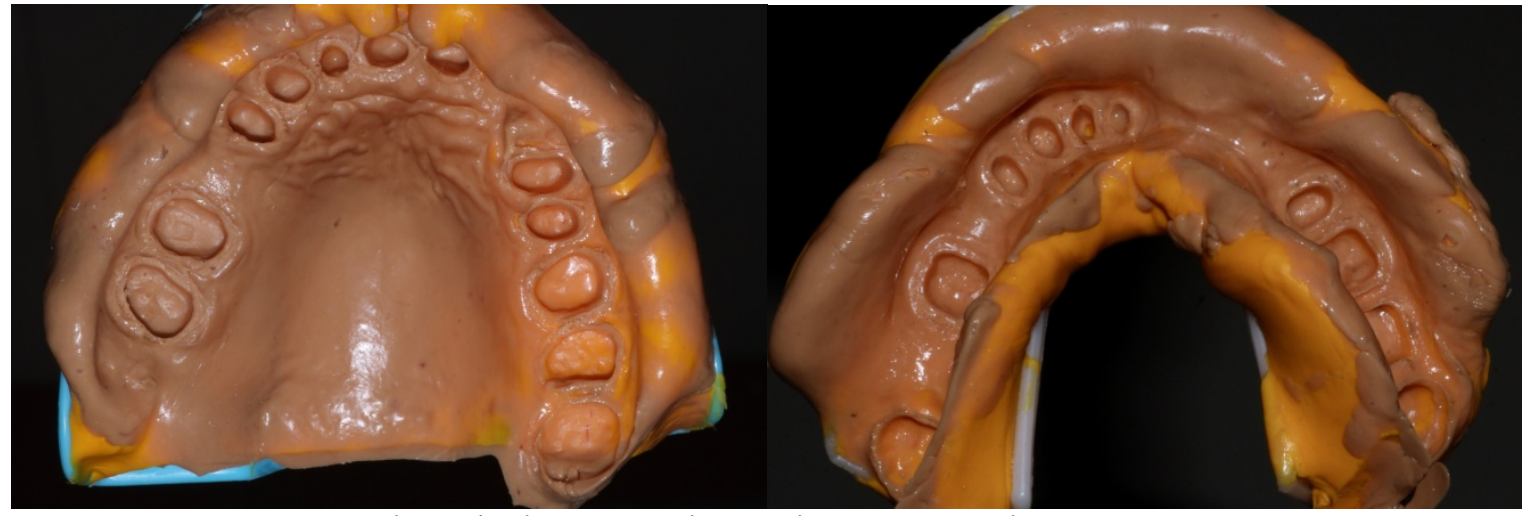

Figure 4: Final Impression maxillary and mandibular arch

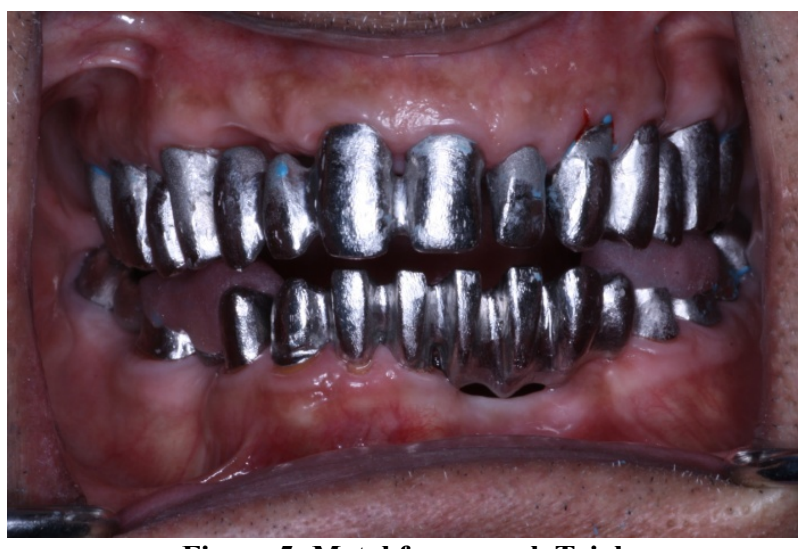

Figure 5: Metal framework Trial

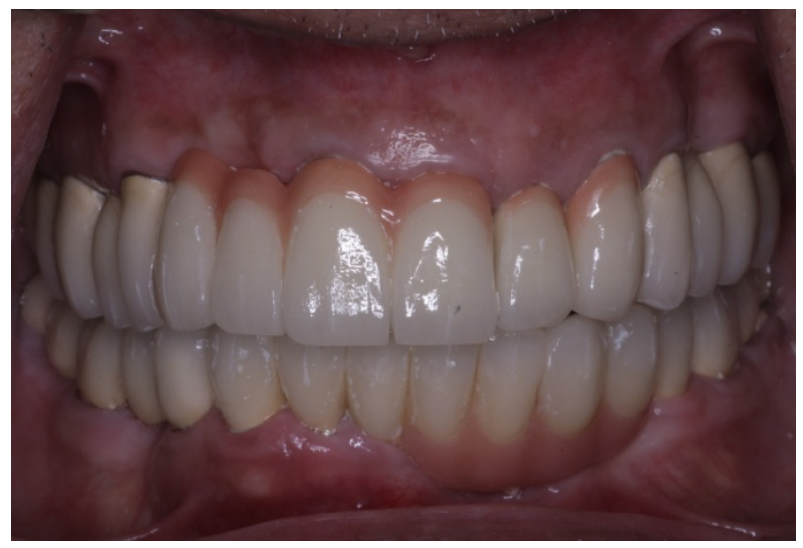

Figure 6: Final Cementation 


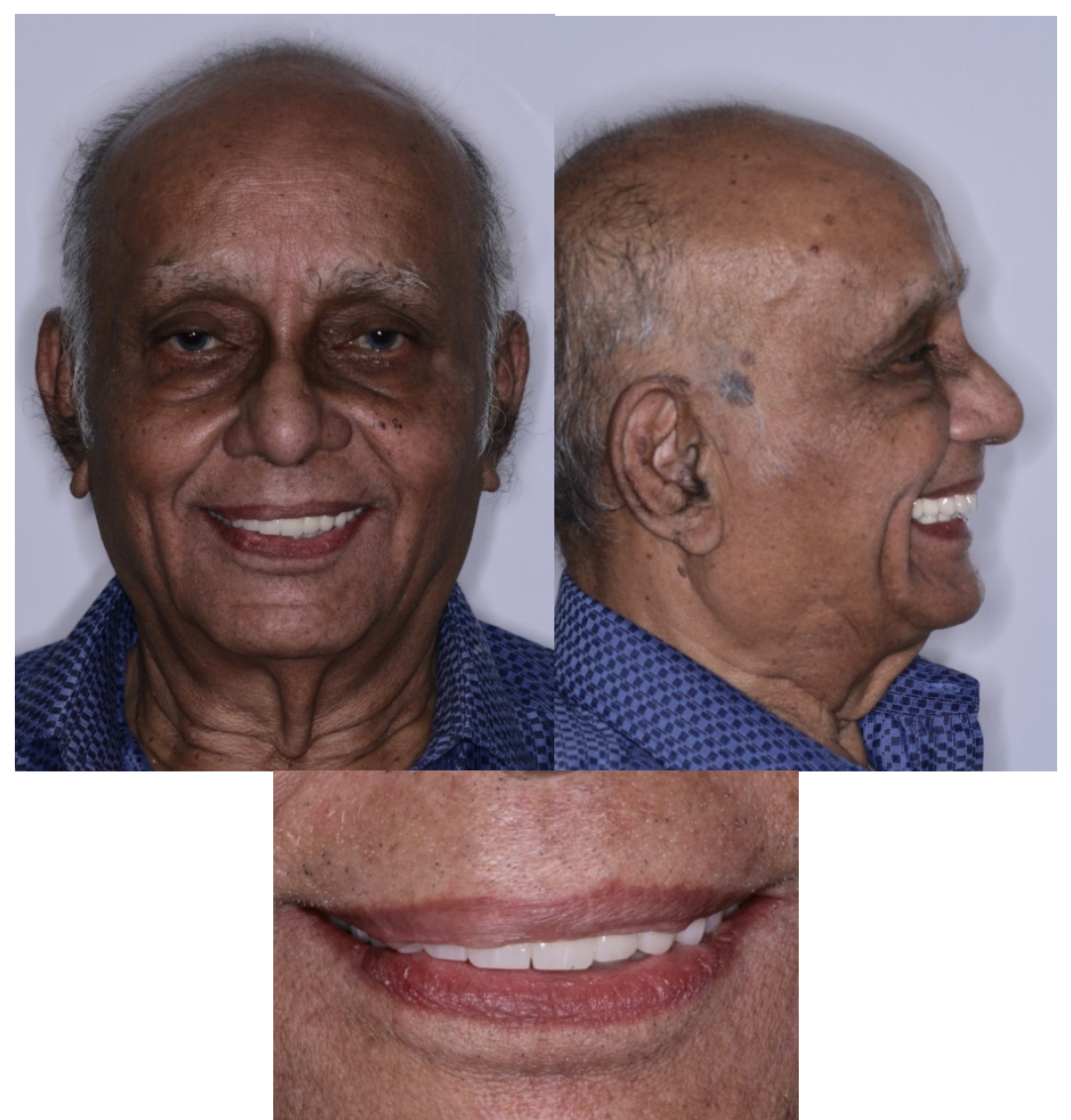

\section{DISCUSSION}

Figure 7: Postoperative extraoral frontal and profile smile, postoperative frontal close up smile

Turner classified the treatment of a severely worn dentition by the evaluation of the loss of Vertical Dimension of Occlusion and space available to restore [9]. This 1894 classification included raising the vertical dimension of occlusion (VDO) compiled with various other procedures [10]. The cause of attrition of teeth is multifactorial, and randomized controlled trials are limited in quantity and quality. This leads to difficulty in decision-making clinically [11].

The severe loss of vertical dimension in this patient was due to the nocturnal bruxism, chronic prolonged tooth wear due to multiple reasons and severe anterior deep bite [12]. This leads to detrimental effects on the tooth as well as the temporomandibular joint [13]. At the start of the treatment the patient had a group function occlusion with no anterior guidance [14]. This leads to the continuous occlusal trauma to the posterior teeth. These challenges were overcome by increasing the vertical dimension of the patient by $6 \mathrm{~mm}$. This increased vertical dimension leads to a change in the patient's profile. The patient has been followed up since 2 years now with no complaints.

A canine guided mutually protected occlusion was provided to the patient to 
reduce the load on the posterior teeth during excursive movements [15].

The major advantage of this procedure would be the stepwise procedure keeping the patient's comfort in mind. Establishing an increased Vertical dimension in the temporary restoration helped in replicating the same for the final restoration which was comfortable for the patient.

\section{CONCLUSION}

Full mouth rehabilitation of patients with collapsed occlusion is complex and multimodal therapy is required to gain successful results. Thus accurate clinical and radiographic examinations, diagnostic wax up and determining the accurate vertical dimension of occlusion are critical. This result can encourage clinicians to seek accurate diagnosis and treatment planning for such patients and treat them accurately.

\section{ACKNOWLEDGEMENTS}

I would like to acknowledge my Department of Prosthodontics of Saveetha Dental College to allow me to proceed with this and help in the provision of the lab support.

\section{REFERENCES}

[1]Kostoulas I, Kourtis S, Andritsakis D, Doukoudakis A. Functional and esthetic rehabilitation in amelogenesis imperfecta with all-ceramic restorations: a case report. Quintessence Int. 2005 May; 36(5): 329-38.
[2]Stober T, Bermejo JL, Rammelsberg P, Schmitter M. Enamel wear caused by monolithic zirconia crowns after 6 months of clinical use. J Oral Rehabil. 2014 Apr; 41(4): 314-22.

[3]Fang-Gang L, Liu-Ning Y. Relation between the change of vertical dimension and the linguistic function in complete denture prosthesis [Internet]. Vol. 22, Journal of Dentistry. 1994. p. 235. http://dx.doi.org/10.1016/03005712(94)90118-x.

[4]Nel JC, Marais JT, Vuuren PAJ. Various Methods of Achieving Restoration of Tooth Structure Loss due to Bruxism [Internet]. Vol. 8, Journal of Esthetic and Restorative Dentistry. 1996. p. 1838. $\quad$ http://dx.doi.org/10.1111/j.17088240.1996.tb00423.x

[5]Carra MC, Huynh N, Morton P, Rompré PH, Papadakis A, Remise C, et al. Prevalence and risk factors of sleep bruxism and wake-time tooth clenching in a 7- to 17-yr-old population [Internet]. Vol. 119, European Journal of Oral Sciences. 2011. p. 386-94. Available from: http://dx.doi.org/10.1111/j.16000722.2011.00846.x

[6]Sierpińska T, Kuć J, Gołębiewska M. Relationships between bruxism and tooth wear index in patients with advanced tooth wear [Internet]. Vol. 66, Prosthodontics. 2016. p. 176-86. 
http://dx.doi.org/10.5604/.1208153.

[7]Vasileva R. Bruxism - description, epidemiology, etiology, classification [Internet]. Vol. 6, Journal of Medical and Dental Practice. 2019. p. 937-41. http://dx.doi.org/10.18044/medinform.2 01854.937.

[8]Bhattarai HK, Shrestha S, Rokka K, Shakya R. Vitamin D, Calcium, Parathyroid Hormone, and Sex Steroids in Bone Health and Effects of Aging. J Osteoporos. 2020 Jun 17; 2020: 9324505.

[9]Bennett A. Tooth wear: classification and methods of treatment [Internet]. Vol. 3, Dental Nursing. 2007. p. 134-7. http://dx.doi.org/10.12968/denn.2007.3. 3.29685

[10] Turner K. Natural Attrition: The Preferred Option? [Internet]. Vol. 30, Journal of Industrial Relations. 1988. p. 363-80. Available from: http://dx.doi.org/10.1177/00221856880 3000302.

[11] Pasam N, Arora A, Gilra S. Full Mouth Rehabilitation: A Simple Approach to a Complex Problem. LAP Lambert Academic Publishing; 2012. 108 p.

[12] Machado NA de G, Fonseca RB, Branco CA, Barbosa GAS, Fernandes Neto AJ, Soares CJ. Dental wear caused by association between bruxism and gastroesophageal reflux disease: a rehabilitation report. J Appl Oral Sci. 2007 Aug; 15(4): 327-33.

[13] Podder A, Saha B, Saha AK, Luna NJ. A Case of Generalized Tooth Wear caused by Bruxism and its Rehabilitation [Internet]. Vol. 10, City Dental College Journal. 2018. p. 40-2. http://dx.doi.org/10.3329/cdcj.v10i1.13 747.

[14] Sidana V, Bhasin S, Makkar M, Pasricha N. Group function occlusion [Internet]. Vol. 3, Indian Journal of Oral Sciences. 2012. p. 124. Available from: http://dx.doi.org/10.4103/09766944.111173.

[15] Miralles R. Canine-guide Occlusion and Group Function Occlusion are Equally Acceptable When Restoring the Dentition [Internet]. Vol. 16, Journal of Evidence Based Dental Practice. 2016. p. 41-3. Available from:http://dx.doi.org/10.1016/j.jebdp. 2016.01.029. 